\title{
Pengaruh Pembiasaan Membaca Al-Qur'an Setiap Pergantian Jam Pelajaran Terhadap Kesiapan Mental Mahasiswa Genta Pare Kediri
}

Erviana Sofyan $^{1}$, Rofiatul Hosna ${ }^{2}$

${ }^{1,2}$ Universitas Hasyim Asy'ari Jombang, Indonesia

\begin{tabular}{ll}
\hline \hline Article Info & \multicolumn{1}{c}{ ABSTRACT } \\
\cline { 2 - 3 } Article history: & $\begin{array}{l}\text { This study discusses the effect of quran reading habits on mental readiness, } \\
\text { this is motivated by the many students who complain about the lessons learned, } \\
\text { Received, Januari 5, } 2019\end{array}$ \\
it is necessary to have mental readiness when receiving lessons, one of which \\
is to get used to reading the Qur'an. This habituation aims to improve the \\
intelligence of the brain and memory of a person, and can nourish various \\
kinds of physical and psychological illnesses. The purpose of this study is (1) \\
To find out and analyze the habit of reading the Qur'an every turn of the lesson, \\
Keywords: \\
(2) To find out and analyze mental readiness, (3) To find out and analyze the \\
influence of the habit of reading the Qur'an every turn lesson hours for \\
students' mental readiness in the Golden English Training Area (GENTA) Pare \\
Kental Readiness \\
Kediri In this study, the study design used a quantitative approach with Expost \\
Facto design and used a type of field research. The population in this study \\
were all at GENTA Pare students. Sampling in this study used Simple Random \\
Sampling. So that every sample withdrawal using this method provides the \\
same opportunity for each member of the population to be a research sample. \\
In this study, data collection uses a questionnaire that serves to measure the \\
level of mental readiness of students who are influenced by the habit of reading \\
the Qur'an.
\end{tabular}

This is an open access article under the $\underline{C C B Y-S A}$ license.

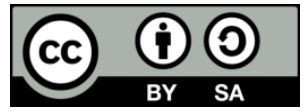

\footnotetext{
Corresponding Author:

Erviana Sofyan,

Program studi Pendidikan Agama Islam,

Universitas Hasyim Asy'ari,

Email: Ervianasofyan01@gmail.com
}

\section{PENDAHULUAN}

Pada era globalisasi banyak kalangan muslim di Indonesia yang melupakan Al-Qur'an, padahal kewajiban seorng muslim terhidap Al-Qur'an adalah menbaca, mempelajari, dan memuliakannya. Akan tetapi, banyak diantara kita terlebih lagi diera modern seperti ini, lebih menyukai kesibukan aktifitas dunia dengan pernak-perniknya yang serba modern dan baru, sehingga kita banyak yang melalaikan dan melupakan Al-Qur'an. Globalisai ini dipicu oleh kemajuan teknologi.

Al-Qur'an adalah rahmat allah yang agung yang diturumkan kepda Nabi Muhammad untuk menyelanatkan manusia dialam semesta. Membaca al-qur'an dengan baik akan mendapatkan rahmat allah yang tiada habisnya, bokan hanya membaca Al-Qur'an saja tetapi hanya dengan kita mendengarkan bacaanbacaan al-qur'an dari handphone atau lainnya Allah telah memberikan rahmatnya.Dalam Jurnal Dakwahku menjelaskan Ayat diatas disebutkan bahwa jika kita mengingat Allah, hati akan menjadi tentram, mengingat disini kita samakan dengan membaca Al-Qur'an. Karna dengan membaca Al-Qur'an kita akan mengingat kekuasaan-kekuasaan Allah SWT. Dan seperti yang diriwayatkan oleh Abu Hurairah ra yakni: "Bahwa Rosulullah saw bersabda: siapa yang mendengar satu ayat daripada kitab Allah (Al-Qur'an) ditulis baginya satu kebaikan yang berlipat ganda. Siapa yang membacanya pula, baginya cahaya dihari kiamat. 
Seperti yang diriwayatkan oleh Abu Hurairah ra yakni: "Bahwa Rosulullah saw bersabda: barang siapa yang mendengar satu ayat daripada kitab Allah (Al-Qur'an), maka dituliis baginya satu kebaikan yang berlepat. Barang siapa yang menbacanya (Al-Qur'an) pula, maka cahaya meneranginya dihari kiamat.

Henry Guntur Tarigan (2013:7) menyebuttkan membaca ialah suatu proses yang diprrgunakan serta dilakukan oleh pembaca untuk menperoleh sebuah pesan, yang ingiin disampaikan oleh penulis media tulis. Allah menurumkan Al-Qur'an bukan tampa tujuan melainkan Allah menurunkan kitab mulia ini yaitu untuk mengiluarkan umat manusiia dari kegel0pan menuju cahaya Islam serta memperbaiki kehidupan manusia. Setiap umat muslim yaqin,bahwa membaca Al-Qur'an ialah termasuk amal yang yang mulia disisi Allah dan akan mendapatkan pahala.

Sebagaimana firman Allah pada surat Al-Alaq ayat 1-5 (Departemen Agama RI) tentang perintah membaca:

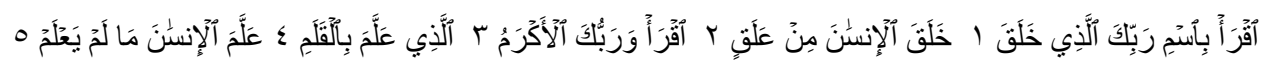

Artinya: 1) Bacalah dengan (menyebut) nama Tuhanmu Yang menciptakan. 2)Dia telah menciptakan manusia dari segumpal darah. 3)Bacalah, dan Tuhanmulah Yang Maha Pemurah. 4)Yang mengajar (manusia) dengan perantaran kalam. 5) Dia mengajar kepada manusia apa yang tidak diketahuinya.

Ayat ini pertama kali diturunkan oleh Allah pada saat Nabi sedang berada di gua Hira' seraya menjalankan ibadah dalam beberapa malam. Ayat tersebut menjelaskan bahwa Allah SWT memerintahkan Nabi agar Membaca. Dalam tafsir Al-Munir, Wahbah az-Zuhaili (1991: 597-598) mengatakan: Kerjakanlah perintah untuk membaca, dan Tuhanmulah yang memerintahkanmu untuk membaca. Menurut Quraish Shihab (2011:456) Membiasakan membaca juga harus dengan ikhlas, Tanpa keiklasan, semua aktifitas akan berakhir dengan sia-sia.

Pembiasaam adalah kegiiatan yang dilakukan secara berulamg-ulang untuk membiasakan seseorang dalam bersikap (Mushlihin Al-Hafizh,2012). Oleh karena itu, membaca Al-Qur'an adalah suatu kewajiban kita sebagai umat muslim, karena Al-Qur'an adalah kitab suci dari Allah yang merupakan pedoman hidup manusiia untuk melaksanakan kehidupan sehari-hari. Syamsu Yusuf (2018:25) menjelaskan Kesehatan mental adalah dimensi kehidupan yang sangat penting, karena dengan kesehatan mental kehidupan akan berjalan dengan baik dan wajar. Adanya kesulitan peserta didik dalam belajar yang disampaikan oleh guru bisa berasal dari faktor tersebut. Agar proses belajar mengajar berjalan lancar perlu adanya solusi untuk memecahkan kesulitan tersebut. Maka perlu adanya kesiapan saat menerima pelajaran, salah satunya mempersiapkan mental atau gangguan-gangguan yang menghambat proses belajar tersebut.

Jika dicermati, megulang-ulamg menbaca Al-Qur'an, banyak mamfaat dan keuntumgan yang luar biasa baik ke fisik maupun psikis seseorang. Pertama, mengulanng-ulang membaca al-Qur'an dapat meningkatkan kecerdasan otak dan pula meningkatkan daya ingat seseorang. Karna dengan mengulangulang otak akan terasah dan akhirnya terbiasa melakukan pekerjaan tersebut. Semakin sering mengulang semakin kuat pula daya ingat seseorang. Kedua membiasakan membaca Al-Qur'an, dapat menyenbuhkan belbagai macam penyikit fisik maupun psikis. Disaat seseorang membaca Al-Qur'an akan merasakan ketenangan jiwa, otomatis ketenangan yang didapat dari membaca Al-Qur'an bisa memperbaiki pada seluruh sistem tubuh yang rusak, dengan izin Allah penyakit tersebut akan sembuh.

Pada GENTA atau Golden English Training Area adalah sebuah lembaga kursus Bahasa Inggris Pare yang menerapkan kegiatan pembiasaan membaca Al-Qur'an 10 minit sebelum pelajaran dimulai setiap hari. Hal iini merupakan pendidikan karakter yang diterapkan lembaga kepada semua mahasiswa. Lembaga ini merupakan salah satu lenbaga yang menamamkan keciintaan pada Al-Qur'an. Walaupun pada lembaga ini khusus belajar Bahasa Inggris, tetapi nilai agama yang ada pada lembaga disini masih terlihat dari berbagai kegiatan keagamaan, diantaranya: kegiatan al-banjari, dan ceramah atau bisa disebut dengan motivasi yang dibawakan langsung dengan Direktur GENTA. Kegiatan ceramah tersebut dilaksonakan setiap seminggu sekali pada hari jum'at malam, degan tujuan untuk memberikan dorongan, motivasi serta kekuatan bagi seluruh Mahasiswa yang sedang dalam keadaan stress, down, gangguan mental, serta banyaknya factor yang menghambat mereka dalam kegiatan belajar.

Banyak mahasiswa GENTA Pare yang timbul penyakit malas untuk membaca Al-Qur'an, karna faktarfaktor yang mempemgaruhi semngat mereka dalam membaca Al-Qur'an seperti: galau, patah hati, beban hafalan yang numpuk atau yang lainnya. Sehingga keadaan ini berakibatkan pada belajar mereka. dan tidak sedikit pula mahasiswa yang gemar membaca Al-Qur'an. Program yang ada di lembaga ini menuntut seluruh mahasiswanya untuk menghafal 25 vocabularies setiap pagi bahkan bisa lebih dari itu. Bukan hanya itu saja selain menghafal vocabularies mahasiswa juga harus bisa memahami bahkan harus menghafal grammer atau yang biasa kita sebut dengan tata bahasa dalam Bahasa Inggris. Dengan begitu mahasiswa akan lancar dalam berbicara Bahasa Inggris. Akibatnya timbullah rasa bosan, malas, rasa tidak percaya diri apabila tidak memenuhi target dan lain sebagainya. Dari sini muncullah beberapa gangguan mental yang terjadi pada diri mahasiswa. Cara yang tepat untuk mengatasi masalah atau gangguan yang dialami 
mahasiswa tersebut adilah dengan membaca Al-Qur'an. Selain bernilai ibadah, membaca Al-Qur'an dapat menyembuhkan berbagai permasalahan penyakit hati apabila dilakukan dengan iklas. Tapi kenyatannya mahasiswa GENTA Pare kurang dalam menghayati bacaan Al-Qur'an apalagi menjadikannya sebuah kebiasaan dalam kehidupan sehari-hari. Ini yang menyebabkan sulitnya mahasiswa menyiapkan hati untuk belajar. Berdasarkan latar belakang masalah diatas, penulis tertarik untuk mengadakan penelitian dengan judul "Pengaruh Pembiasaan Membaca Al-Qur'an Setiap Pergantian Jam Pelajaran Terhadap Kesiapan Mental Mahasiswa Di Golden English Training Area (GENTA) Pare Kediri”.

\section{METODE}

Jenes penelitian yang digunakan peneliti dalam penelitian iini menggunakan desain Expost Facto degan jenis penelitian field research, dimana pengumpulan data atau informasinya dilaksanakan secara langsung kepada para responden dilapangan atau di tempat responden beraktifitas. Teknik pengumpulan data dalam penelitan ini peneliti hanya mengunakan tiga teknik pegumpulan data, yang umum digunakan oleh penelitipeneliti lainnya dalam metode pendekatan kuantitatif, yaitu: teknik observasi, teknik angket dan dokumentasi, Teknik analiisis data dalam penelitian kuamtitatif mengunakan statistik. Tetdapat adia dua macan statistik yang digunkan untuk menganalisis menganalisis data yaittu, statistik deskriptif, dan statistik inferensial. Peneliitian ini, peneliti menggunakan statistik inferensial degan jeniss regresi tunggal (satu variabel bebas dan satu variabel terikat) untuk mengetahui seberapa besar pengarunya variabel $\mathrm{X}$ tehadap variabel Y.

\section{HASIL DAN PEMBAHASAN}

Untuk mengetahui ada dan tidaknya hubungan antara pembiasaan membaca Al-Qur'an terhadap kesiapan mental di Golden English Training Area maka peneliti menggunakan data kuantitatif dengan berbagai analisis.

Dari 15 item pernyataan, seelah diujii validitas degan progriam SPSS 16.0 for Windows untok variabel $\mathrm{X}$ dan Y senua hitam dinyataan valid. Adapum nilei cronbach's alpha $\mathrm{X}=0,885$ dan nilai cronbach's alpha $\mathrm{Y}=0,737$ yang berarti angket yamg digunakan dalan penelitian ini dinyatakan reliable

Pengujian asumsi dasar ini dilakukan sebelum akan melakukan analisis regresi sederhana. Hasil output dari Test of Homogeneity of variances dapat diketahui bawa signiifikasi sebsar 0.065. nilai ini memunjukan bahwa nilai sig > 0.05 level of significant, maka dapat disimpullkan bahwa data mempunya varian varian yang sama. Untuk memprediksi tingkat kesiapan mental yang dipengaruhi oleh pembiasaan membaca AlQur'an diketahui dalam uji linieritas, F hitung > F tabel, dengan nilai F hitung 43.870 dan F tabel sebesar 4.11 maka Ho ditolak. Artinya ada hubungan linier antara variable pembiasaan membaca Al-Qur'an terhadap kesiapan mental.

Hasil analisis dalam pengujian regresi sederhana adalah Ha diterima dan Ho ditolak. Adapun hasil nilei koefisien deterninasi R Square sebesar 0.542 artinya 54.2\% variable dependen (kesiapan mental) telah memberikan pengaruh terhadap pembiasaan menbaca Al-Qur'an. Dan ssanya $45.8 \%$ dipegaruhi oleh fator yang lain. Daki uji anova $f$ test didapat $f$ hitung sebesar 43.870 dengan nilai sinifikan 0.000. kaena nilai simifikan jauh lebeh kecil dari 0.05 maka model Regressional yang digunakan sodah layak untuk dipakei meguji linier tes. Jadi terdapat pengaruh antara pembiasaan membaca Al-Qur'an terhadap kesiapan mental mahasiswa GENTA.

\section{KESIMPULAN}

Pembiasaan membaca Al-Qur'an dijalankan dengan "cukup baek". Hal ini dakat dikatakam bahwa pembiiasaan membaca Al-Qur'an mahasiswa Golden English Training Area tergolong cukup baik dengan frekuensi 21 prosentase 54\%. Kesiapan mental mahasiswa Golden English Training Area dapat dikatakan "sangat baik".Hal ini dapat dikatakan bahwa kesiapan mental mahasiswa Golden English Training Area tergolong sangat baik dengan frekuensi 25 prosentase $64 \%$.

Berdasarkan hasil dari perhitungan tabel output SPSS menunjukkan nilai koefisien korelasi pembiasaan membaca Al-Qur'an terhadap kesiapan mental adalah $r=0.737$,sedagan $r$ tabbel dengan Dk $n-1$ sehingga 39-1 = 38 tingkat kepercayaan 95\% maka didapat $r$ tabeel 0.320. karna $r$ hitiung lebeh besrr dari $r$ tabel maks Ha ditrima yang berrrti terdapat korelasi antara pembiasaan membaca Al-Qur'an dengan kesiapan mental. pada kolom Sig.(2-tailed) sebesar $0.000<0.05$ (lepel of signiifikan). Maka daoat disimpullkan bahwa: "Terdapat pengaruh yang positif dan signifikan antara pembiasaan membaca Al-Qur'an setiap pergantian jam pelajaran terhadap kesiapan mental Mahasiswa di Golden englis Training Area Pare Kediri”. 


\section{REFERENSI}

Amanna, Fattich Alviani. 2015, 'Pengarruh Kebiasaan Menbaca Al-Qur'an tergadap Prestasi Belajar Pendidikan Agama Islam Siswa Kelas X Di Madrasah Aliyah Neghri Kota Madiun', Skipsi, Malang: Universitas Islam Negri Maulana Malik Ibrahim

Aziz, Moh. Ali. 2018, Mengenal Tuntas Al-Qur'an, Surabaya: Imtiyaz

Darmawam, Deni. 2016, Metode Penelitian Kuamttitatif, Bandung: Renaja Rosdakarys.

Dakwahku, Jurnal. 2016 “Keutamaan Membaca Al-Qur'an”, http://jurnaldakwahku.blogspot.com,

Edwin N, Mustafa. dan Hardius Usman. 2007 Proses Penelitian Kuantitatif, cet 2, Jaksrta: Lenbaga Penebitt Fakulta Eknimi Univrsitas Indonesia

Fathurrosyid dan Samheri (eds). 2015, Studi Al-Qur'an, Surabaya: Kopertais IV Press

Jalaluddin, 2016, Psikologi Agama, Cet 18, Jakarta: Raja Grafindo Persada

Nawawi, Imam. 2018, “At-Tibyaanu fi Adabi Hamalati Al-Qur'an” terj: Umar Mujtahid, Solo: Pustaka Qur'an Sunnah

Nirwan, Tri Sutasmi, dkk. 2016, "Hubugan Antaraa Kesispan Mental Dengan Motivasi Belajar Pafa MataPelajaran Biologi”, journal Biotek Volume 4 Nomor 1

Notosoedirdjo, Moeljono. dan Latipun. 2017, Kesehatan Mental,Cet 2, Malang: Universitas Muhammadiyah Malang

Sugiono. 2017, Stiatistika Untuk Penelitian, Cet 29, Banndung: Alfabeta

Sugiono, 2016, Metode Penelitian: Kuamtitatif, Kualitatiif dan R\&D, Bamdung: Alfabeta

Tarigan, Hemry Guntur. 2013, Menbacaa sebagasuatu Keterampilan Berbahasa, Bandung: CV Angkasa

Yusuf, Syamsu. 2018, Kesehatan Mental, Bandung: Rosdakarya, Team Kreatif BUMP Fathul Ulum. 2018, Seribu Satu Tanya Jawab Fiqh, Kediri: Ats-Tsuroyya Press 